\title{
Identification and Mapping of DNA Markers Linked to Eastern Filbert Blight Resistance from OSU 408.040 Hazelnut
}

\author{
Vidyasagar R. Sathuvalli, Shawn A. Mehlenbacher', and David C. Smith \\ Oregon State University, Department of Horticulture, 4017 Agricultural \\ and Life Sciences Building, Corvallis, OR 97331
}

Additional index words. disease resistance, Anisogramma anomala, marker-assisted selection, simple sequence repeat, filbert

\begin{abstract}
Eastern filbert blight (EFB) of European hazelnut (Corylus avellana L.), caused by the pyrenomycete Anisogramma anomala (Peck) E. Müller, is a major disease problem and production constraint in Oregon's Willamette Valley. Host genetic resistance is viewed as the most economical means of controlling this disease. Marker-assisted selection has been extensively used for 'Gasaway' resistance in the hazelnut breeding program at Oregon State University (OSU). Concern over potential breakdown of this single resistance gene prompted a search for new sources of resistance. Selection OSU 408.040 showed no signs or symptoms of the fungus after a series of disease inoculations, and resistance was transmitted to half of its offspring, indicating control by a dominant allele at a single locus. In this study, we identified six random amplified polymorphic DNA (RAPD) and 11 simple sequence repeat (SSR) markers linked to EFB resistance from OSU 408.040. The new markers supplement the previously identified amplified fragment length polymorphism (AFLP) markers. A linkage map constructed in the progeny OSU $245.098 \times$ OSU 408.040 spanned a distance of $19.5 \mathrm{cM}$ with the resistance locus cosegregating with AFLP marker A8-150 and located between SSR markers LG675 and LG682. Using SSR markers as anchor loci, OSU 408.040 resistance was assigned to linkage group 6 (LG6). Comparison with the previously mapped 'Gasaway' resistance locus showed that resistance from OSU 408.040 maps to the same location.
\end{abstract}

Hazelnut or filbert is the fruit of plants in the genus Corylus L., which are members of the family Betulaceae. European hazelnuts (C. avellana) are deciduous shrubs or small trees native to the northern temperate zone. Major producers of hazelnuts are Turkey, Italy, United States, Spain, Azerbaijan, Georgia, France, Greece, and Russia. The United States ranks third in world production with acreage centered in Oregon's Willamette Valley. Its 42,640 t represents 5.6\% (FAOStat, 2009) of the world's hazelnuts.

One of the threats to Oregon's hazelnut industry is the fungal disease EFB caused by the pyrenomycete Anisogramma anomala (Peck) E. Müller. The fungus is an obligate biotroph with a 2-year life cycle (Pinkerton et al., 1995) that infects many species in the genus Corylus. On the commercially important European hazelnut, it causes severe stem cankers leading to rapid yield losses and eventual tree death in 5 to 12 years if proper control measures are not practiced (Pinkerton et al., 1993). The pathogen is native to eastern North America where its host is wild American hazel (C. americana Marsh.). Its life cycle has

Received for publication 30 Jan. 2012. Accepted for publication 3 Mar. 2012.

${ }^{1}$ To whom reprint requests should be addressed; e-mail Mehlenbs@hort.oregonstate.edu. been well documented (Johnson et al., 1996; Pinkerton et al., 1992, 1998a, 1998b; Stone et al., 1992). Ascospores released from perithecia are dispersed by splashing rains and active discharge that occurs during prolonged periods of branch wetness. The ascospores germinate and produce hyphae that directly penetrate young growing shoots, permeate and destroy the cambial layer, and eventually produce visible cankers having ascospores within ascostromata $12-16$ months after infection. Since first being noticed in 1968 by a grower in southwest Washington, EFB has moved southward at an average rate of 2 to $3 \mathrm{~km}$ per year (Davison and Davidson, 1973; Pinkerton et al., 1995). Current control measures include scouting, pruning of the infected branches at least $30 \mathrm{~cm}$ below the cankers, and routine fungicide treatments beginning at budbreak and continuing at 2-week intervals during growth of new shoots (Pscheidt, 2006). Because of environmental concern over the use of fungicides and the high cost of applications, host genetic resistance is viewed as the most desirable and economical means of controlling this disease (Mehlenbacher, 1994).

Complete resistance to EFB was first discovered in C. avellana 'Gasaway', an obsolete pollenizer that was found free of symptoms in a heavily infected 'DuChilly' orchard (Cameron, 1976). The resistance from 'Gasaway', controlled by a dominant allele at a single locus (Mehlenbacher et al., 1991), has been extensively used in the hazelnut breeding program at OSU. Most advanced selections and recently released cultivars and pollenizers carry 'Gasaway' resistance. Greenhouse inoculation studies (Chen et al., 2007; Coyne et al., 1998; Lunde et al., 2000; Sathuvalli et al., 2010) identified several additional $C$. avellana selections resistant to EFB. Selection OSU 408.040, grown from seeds labeled "Weschcke hybrid" collected at the research farm of the University of Minnesota in 1987, showed no signs or symptoms of the fungus after a series of greenhouse inoculations or exposure of potted trees under structures topped with diseased wood from 1995 to 2000 (Mehlenbacher, unpublished data). OSU 408.040 trees are not precocious and are low-yielding and highly susceptible to big bud mite (primarily Phytoptus avellanae Nal.). Its nuts mature early but are small and long and the kernels blanch poorly. Chen et al. (2005) showed that OSU 408.040 transmits a high level of resistance to half of its offspring when crossed to susceptible selections, indicating control by a dominant allele at a single locus at which OSU 408.040 is heterozygous. Thus, OSU 408.040 may provide an additional source of EFB resistance.

Current EFB evaluation methods are slow and time-consuming, because cankers cannot be scored until 16-20 months after inoculation. Identification of molecular markers closely linked to EFB resistance alleles would greatly facilitate the development of new cultivars. Random amplified polymorphic DNA and SSR markers linked to EFB resistance have been identified for three sources: 'Gasaway', 'Ratoli' from Spain, and OSU 759.010 from the Republic of Georgia (Mehlenbacher et al., 2004; Sathuvalli et al., 2011a, 2011b; Sathuvalli and Mehlenbacher, unpublished data). In the OSU hazelnut breeding program, markerassisted selection (MAS) uses RAPD markers 152-800 and 268-580 for 'Gasaway' resistance, G17-800 for 'Ratoli' resistance, and 695-1800, F08-700, and 373-700 for OSU 759.010 resistance, respectively. These three resistance loci segregate independently and have been assigned to LG6, LG7, and LG2, respectively (Mehlenbacher et al., 2006; Sathuvalli et al., 2011a, 2011b).

The potential breakdown of single resistance genes is always a concern in disease resistance breeding. Molnar et al. (2010a, $2010 \mathrm{~b}$ ) showed that an isolate from Michigan was able to infect 'Gasaway' and OSU 408.040 in New Jersey. One strategy for durable resistance is the pyramiding of two or more resistance genes in a single cultivar. Pyramiding of the three resistance loci mapped to date would be straightforward facilitated by linked DNA markers.

In this study, we identified RAPD and SSR markers linked to resistance from OSU 408.040. The new markers, and previously identified AFLP markers (Chen et al., 2005), were mapped and assigned to a linkage group. The map for the OSU 408.040 resistance region was compared with the map 
for the 'Gasaway' resistance region using common SSR markers.

\section{Materials and Methods}

Plant materials. In 1997, two controlled crosses of the susceptible selections OSU 245.098 and OSU 474.013 as female parents and OSU 408.040 as the male parent were made generating 125 and 65 seedlings in progenies designated 97035 and 97036, respectively (Chen et al., 2005). EFB susceptibility of the seedlings was determined by greenhouse inoculation followed by enzyme-linked immunosorbent assay (Coyne et al., 1996). The disease response and AFLP marker data of Chen et al. (2005) were used in this study. We used seedlings from progenies 97035 and 97036 to identify new DNA markers linked to resistance from OSU 408.040.

DNA extraction. Two methods of DNA extraction were used in this study. For the initial screening of primers, large quantities of DNA template were essential. From progeny 97035, fresh young leaves from five susceptible seedlings, five resistant seedlings, and the parents were collected during Spring 2005. The leaves were ground in liquid nitrogen and held at $-80^{\circ} \mathrm{C}$ until DNA extraction. DNA was extracted using a Puregene DNA isolation kit (Gentra Systems, Minneapolis, MN) according to the manufacturer's instructions. For mapping, fresh young leaves of 95 seedlings of progeny 97035 and 60 seedlings of progeny 97036 were collected from the field in Spring 2005. DNA was extracted following the method of Lunde et al. (2000) with slight modifications and no RNAase treatment. The DNA extracted by both methods was quantified using a spectrophotometer (ND-1000; Nano Drop Technologies, Wilmington, DE).

Random amplified polymorphic DNA analysis. Three resistant seedlings, three susceptible seedlings, and the parents of progeny 97035 were used to screen primers and search for markers potentially linked to EFB resistance. A total of 900 primers was screened: all primers in kits $\mathrm{AF}-\mathrm{AZ}$ and selected primers in kits A-AE (Eurofins MWG Operon Technologies, Huntsville, AL) and 380 primers in sets 1-800 from the Michael Smith Laboratories of the University of British Columbia (Vancouver, Canada). The selected primers were those that generated polymorphic markers in a population segregating for resistance from 'Gasaway' (Mehlenbacher et al., 2006). Primers that generated a band present in the resistant parent and all three resistant seedlings but absent in the susceptible parent and all three susceptible seedlings were used for mapping the whole population. Primers that showed recombination in one of six seedlings in the initial screening were further investigated in a group of 24 additional seedlings. The markers that showed less than $15 \%$ recombination with the resistance phenotype were then amplified in the remaining seedlings of the population.

Polymerase chain reactions (PCRs) were performed in a $15-\mu \mathrm{L}$ volume containing 0.4 $\mu \mathrm{M}$ of primer, $3.5 \mathrm{ng}$ of template DNA, $0.4 \mathrm{U}$ of Biolase DNA polymerase (Biolase USA, Randolph, MA), $1.5 \mathrm{~mm} \mathrm{MgCl} 2,120 \mu \mathrm{M}$ each of dATP, dCTP, dGTP, and dTTP, and the $1 \times$ ammonium-based buffer supplied by the manufacturer (Mehlenbacher et al., 2004). Ninetysix reactions were run simultaneously using Geneamp ${ }^{\circledR}$ PCR System 9700 thermal cyclers (Applied Biosystems/Perkin-Elmer, Foster City, CA). The thermal cycler program consisted of an initial $5 \mathrm{~s}$ at $95^{\circ} \mathrm{C}$ and $1 \mathrm{~min} 55 \mathrm{~s}$ at $92^{\circ} \mathrm{C}$ followed by 40 cycles of $5 \mathrm{~s}$ at $95^{\circ} \mathrm{C}, 55 \mathrm{~s}$ at $92{ }^{\circ} \mathrm{C}, 1 \mathrm{~min}$ at $35^{\circ} \mathrm{C}, 2 \mathrm{~min}$ at $72{ }^{\circ} \mathrm{C}$, then $7 \mathrm{~min}$ at $72^{\circ} \mathrm{C}$, ending with an indefinite hold at $4{ }^{\circ} \mathrm{C}$ until retrieved from the thermal cycler. During the first five cycles, the ramp time from 35 to $72{ }^{\circ} \mathrm{C}$ was minimized to $30 \%$ of maximum to reduce non-specific binding of primers (Mehlenbacher et al., 2004). When necessary to improve repeatability of scoring, primer and $\mathrm{MgCl}_{2}$ concentrations were adjusted. Amplification products were separated by electrophoresis on $2 \% \mathrm{w} / \mathrm{v}$ agarose (ISC Bioexpress, Kaysville, UT), stained with ethidium bromide (Sigma-Aldrich, St. Louis, MO), and photographed using a ultraviolet imaging system (UVP, Upland, CA).

Simple sequence repeat analysis. A total of 135 SSR markers was chosen from those previously identified (Bassil et al., 2005a, 2005b; Boccacci et al., 2005; Gürcan and Mehlenbacher, 2010a, 2010b; Gürcan et al., 2010) based on polymorphic information content, ease of scoring, and suitability for multiplexing. SSR primer pairs were initially screened against the parents of progeny 97035 (OSU 245.098 and OSU 408.040) to identify polymorphic markers. The 58 SSR markers that were polymorphic between the parents, and heterozygous in OSU 408.040, were used for analysis of cosegregation with disease phenotype. Each allele at each SSR locus was scored as present (1) or absent (0). Disease response was scored similarly, resistant (1) or susceptible (0). Initially, 30 seedlings (15 resistant and 15 susceptible) were genotyped with SSRs as described by Sathuvalli and Mehlenbacher (2011). Correlation coefficients were calculated using the PROC CORR of SAS (Version 9.2; SAS Institute, Cary, NC), and SSR markers showing a correlation coefficient with disease phenotype greater than 0.5 were investigated further. The SSR markers had been previously mapped (Gürcan and Mehlenbacher, 2010a; Gürcan et al., 2010; Mehlenbacher et al., 2006; Sathuvalli and Mehlenbacher, unpublished data), so once the linkage group (LG) carrying the resistance locus had been identified, all polymorphic SSR markers in the linkage group were used for mapping. Eleven SSRs from LG6 were mapped in progeny 97035.

Data analysis and construction of the linkage map. RAPD markers potentially linked to disease resistance were scored using 95 seedlings from progeny 97035 and 60 seedlings from progeny 97036 . Similarly, SSR markers in LG6 were scored on 95 seedlings from progeny 97035. Linkage maps were constructed using JoinMap Version 4.0 (Van Ooijen and Voorrips, 2006) as described by Sathuvalli et al. (2011a) using RAPDs, SSRs, and the AFLP markers previously identified by Chen et al. (2005). The maps for progeny 97035 and OSU $252.146 \times$ OSU 414.062, which segregates for resistance from 'Gasaway', were aligned and compared using SSR markers on LG6.

\section{Results}

Random amplified polymorphic DNA markers. A total of 900 primers was screened using three resistant seedlings, three susceptible seedlings, and the parents of progeny 97035 , and 34 potential markers were initially identified. Further investigation and mapping identified six markers linked to resistance, two in coupling (AJ01-290 and 335-670) and four in repulsion $(538-780 \mathrm{R}$, AT08-1000R, AU09390R, and A04-200R). The marker designations are the primer followed by the amplified polymorphic band size followed by an " $\mathrm{R}$ " if linked in repulsion. To confirm the reproducibility and robustness of the RAPD markers, the analysis was also carried out on 60 seedlings of progeny 97036. All of the RAPD markers scored in progeny 97035 were validated in progeny 97036, although for marker 335-670, electrophoresis for $9 \mathrm{~h}$ at $90 \mathrm{~V}$ was required to separate two bands of similar size.

Simple sequence repeat markers. A total of 135 SSR markers were initially screened for polymorphism between the parents OSU 408.040 and OSU 245.098. Of these, 58 were polymorphic and heterozygous in OSU 408.040. In the initial analysis using 15 resistant and 15 susceptible seedlings of progeny 97035, two SSRs had correlation coefficients 0.5 or greater with disease response. At loci KG821 and A614, allele sizes 261 and 150 , respectively, were linked to resistance. KG821 had not previously been mapped, but A614 had been assigned to LG6 by Gürcan et al. (2010). To more precisely map the resistance locus, 23 SSRs recently developed from bacterial artificial chromosome sequences (Sathuvalli and Mehlenbacher, unpublished data) were also analyzed. Of the $23 \mathrm{SSR}$, nine were polymorphic between the parents and heterozygous in OSU 408.040 and were scored in progeny 97035 . A total of 11 SSRs were scored in progeny 97035 but were not validated in progeny 97036 .

Linkage map construction and identification of resistance region. A linkage map was constructed using the six newly identified RAPD markers, 11 SSR markers, disease phenotype, and the five AFLP markers of Chen et al. (2005) using JoinMap 4.0 (Van Ooijen and Voorrips, 2006). All of these markers remained in a single group at logarithm of odds 10.0 indicating strong linkage. The map spanned a distance of $19.5 \mathrm{cM}$ with the resistance locus cosegregating with AFLP marker A8-150 and located between SSR markers LG675 and LG682 (Fig. 1, left). All markers showed a good fit to the expected ratio of 1:1, and mean chi-square contributions of the markers from the JoinMap output were all low (Table 1), indicating good fit. Disease response and four markers segregated as a block with no 


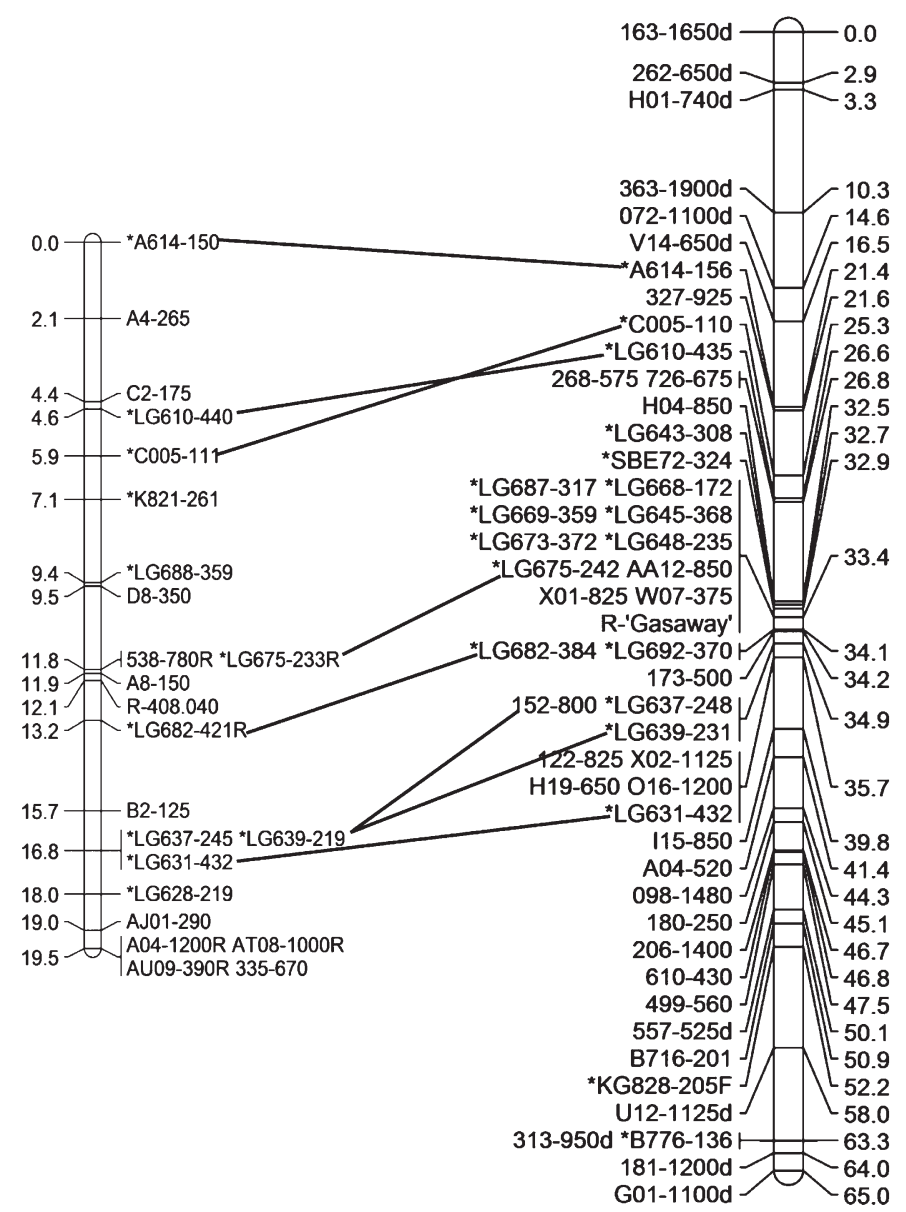

Fig. 1. Comparison of maps for linkage group 6 in Corylus avellana progenies OSU $245.098 \times$ OSU 408.040 (left) and OSU $252.146 \times$ OSU 414.062 (right) with SSR markers indicated by an asterisk $(*)$ EFB resistance from OSU 408.040 and 'Gasaway' are both placed between SSR markers LG675 and LG682. SSR = simple sequence repeat; EFB = eastern filbert blight.

Table 1. Marker position, mean chi-square contributions, and their segregation in Corylus avellana progeny 97035 (OSU $245.098 \times$ OSU 408.040).

\begin{tabular}{lcccccc}
\hline Locus & Position & Mean chi square & Absent (no.) & Present (no.) & Chi square & $P(1: 1)$ \\
\hline A614-150 & 0.00 & 0.20 & 44 & 51 & 0.52 & 0.47 \\
A4-265 & 2.11 & 0.20 & 39 & 50 & 1.36 & 0.24 \\
C2-175 & 4.43 & 0.06 & 39 & 50 & 1.36 & 0.24 \\
LG610-440 & 4.61 & 0.07 & 42 & 53 & 1.27 & 0.26 \\
C005-111 & 5.85 & 0.10 & 41 & 54 & 1.78 & 0.18 \\
KG821-261 & 7.15 & 0.09 & 41 & 52 & 1.30 & 0.25 \\
LG688-359 & 9.40 & 0.04 & 44 & 51 & 0.52 & 0.47 \\
D8-350 & 9.47 & 0.02 & 41 & 49 & 0.71 & 0.40 \\
538-780R & 11.76 & 0.07 & 44 & 50 & 0.38 & 0.54 \\
LG675-233R & 11.77 & 0.07 & 44 & 51 & 0.52 & 0.47 \\
A8-150 & 11.94 & 0.04 & 41 & 48 & 0.55 & 0.46 \\
Resistance & 12.13 & 0.47 & 22 & 23 & 0.02 & 0.89 \\
LG682-421R & 13.20 & 0.19 & 44 & 50 & 0.38 & 0.54 \\
B2-125 & 15.71 & 0.21 & 40 & 50 & 1.11 & 0.29 \\
LG637-245 & 16.82 & 0.08 & 45 & 50 & 0.26 & 0.61 \\
LG639-219 & 16.82 & 0.08 & 45 & 50 & 0.26 & 0.61 \\
LG631-432 & 16.82 & 0.08 & 45 & 50 & 0.26 & 0.61 \\
LG628-219 & 17.96 & 0.07 & 44 & 51 & 0.52 & 0.47 \\
AJ01-290 & 19.01 & 0.11 & 43 & 52 & 0.85 & 0.36 \\
A04-1200R & 19.50 & 0.10 & 42 & 53 & 1.27 & 0.26 \\
AT08-1000R & 19.50 & 0.10 & 42 & 53 & 1.27 & 0.26 \\
AU09-390R & 19.50 & 0.10 & 42 & 53 & 1.27 & 0.26 \\
\hline
\end{tabular}

recombination: 538-780R, LG675, A8-150, and LG682. Map distances in this region are not precise because of the limited disease response data (45 of 95 seedlings) and a few missing AFLP marker scores.

\section{Discussion}

In plant breeding, genetic markers can increase the efficiency and precision of selection for pest and disease resistance. Molecular markers are useful when the resistance has low heritability, for pyramiding genes, and also to supplement disease screening methods that are slow or laborious. Also, MAS allows selection for resistance in the absence of the pathogen and thus avoids its spread. For EFB in hazelnut, the time from the initial inoculation to expression of disease symptoms is greater than 16 months. EFB response scores are not always accurate, because susceptible seedlings can escape infection, and resistant seedlings occasionally develop small cankers. These reasons prompted us to search for genetic markers linked to EFB resistance. Indeed, DNA markers linked to different EFB resistance loci have been identified and are being used for MAS in the OSU hazelnut breeding program (Mehlenbacher et al., 2004; Sathuvalli et al., 2011a, 2011b).

Chen et al. (2005) studied segregation for disease response in seedlings of OSU 408.040 and showed that resistance is controlled by a single dominant gene. Furthermore, Chen et al. (2005) identified five AFLP markers linked to resistance in the cross OSU $245.098 \times$ OSU 408.040. Three of these markers were also present in a second progeny, OSU $474.013 \times$ OSU 408.040. However, the direct use in MAS of these AFLP markers is prohibited by the technique's demands and high cost. Practical application of large-scale MAS requires marker assays that are high-throughput, cost-effective, reliable, and easy to score. This led us to search for other DNA markers linked to resistance. We identified six RAPD markers linked to resistance in OSU 408.040, two in coupling (AJ01-290 and 335-670) and four in repulsion $(538-780 \mathrm{R}$, AT08-1000R, AU09-390R, and A04-1200R). The markers linked in coupling have potential for direct use in MAS. Because RAPDs are generated arbitrarily from different parts of the genome (Williams et al., 1990) and reproducibility is a concern, we confirmed the reproducibility and robustness of the RAPD markers using 60 seedlings of progeny 97036 (OSU $474.013 \times$ OSU 408.040). All six RAPD markers were validated in progeny 97036, although for marker 335-670, electrophoresis for $9 \mathrm{~h}$ at 90 $\mathrm{V}$ was required to separate two bands of similar size. Marker AJ01-290 is suitable for use in MAS but is $\approx 7 \mathrm{cM}$ from the resistance locus.

Analysis of cosegregation of SSR markers and disease phenotype initially identified two (KG821-261 and A614-150) linked to resistance. The marker A614 had been previously mapped to LG6 in a mapping population generated by Mehlenbacher et al. (2006), thus indicating that EFB resistance from OSU 408.040 is on LG6. A total of 11 SSR markers was mapped to the resistance region with LG682, LG675, and LG688 closest to resistance (less than $3.0 \mathrm{cM}$ ) (Fig. 1, left). The OSU hazelnut breeding program has used 'Gasaway' resistance extensively in breeding, and most recently released cultivars and pollenizers, and advanced selections in trials carry resistance from 'Gasaway'. However, Molnar et al. (2010b) showed that an isolate from Michigan can infect 'Gasaway', prompting greater concern about potential breakdown 
of resistance and a continued search for new resistance sources. Eventually, we envision the pyramiding of two or more resistance genes in a single cultivar for durable resistance. Availability of different sources of resistance and DNA markers linked to resistance, and knowledge of their map locations, greatly facilitates pyramiding. Previous studies have assigned three sources of resistance to LGs: 'Gasaway' resistance to LG6 (Mehlenbacher et al., 2006), 'Ratoli' resistance to LG7, and OSU 759.010 resistance to LG2. In this study, we found that resistance from OSU 408.040 is also on LG6 and that it maps to the same region as 'Gasaway' resistance (Fig. 1). The two maps show the same SSR markers in the same order with LG675 and LG682 flanking the resistance loci. Molnar et al. (2010a) found that inoculation with an isolate from Michigan led to a sunken lesion lacking stromata on both 'Gasaway' and OSU 408.040 indicating that they may carry the same $R$ gene.

Disease resistance genes confer resistance to different pathogens and have been assigned to groups based on similarity in their DNA sequences. More than $55 R$ genes have been cloned from different plant species and assigned to groups based on similarity in their DNA sequences (Van Olijen et al., 2007). The vast majority of cloned $R$ genes encode nucleotide binding site and leucine-rich repeat proteins. Mapping studies of $R$ genes and resistance gene analogs have shown a tendency for them to occur in clusters. Michelmore and Meyers (1998) explained that clusters of $R$ genes are reservoirs of genetic variation from which new pathogen specificity can evolve through gene duplication, ectopic recombination, unequal crossing-over, or diversifying selection. Because we have disease phenotypes for only 45 of 95 seedlings, our maps are not sufficiently precise to conclude if the locations of the 'Gasaway' and OSU 408.040 resistance loci are the same or nearby members of an $R$ gene cluster. Future studies on map-based cloning of resistance ('Gasaway' and OSU 408.040) and/or a candidate gene approach of mapping resistance gene analogs will help in this determination.

\section{Conclusion}

We identified new RAPD and SSR markers linked to EFB resistance from OSU 408.040, of which one RAPD marker (AJ01-290) has potential for use in MAS. The SSR markers linked to resistance can be effectively used as genetic markers to trace the resistance allele when pyramiding two or more resistances in a single cultivar. The resistance locus was assigned to LG6, and it mapped to the same location as 'Gasaway' resistance. Future studies are essential to confirm if resistance from 'Gasaway' and OSU 408.040 are the same or nearby members of an $R$ gene cluster.

\section{Literature Cited}

Bassil, N.V., R. Botta, and S.A. Mehlenbacher. 2005a. Microsatellite markers in hazelnut: Isolation, characterization and cross-species amplification. J. Amer. Soc. Hort. Sci. 130:543-549.

Bassil, N.V., R. Botta, and S.A. Mehlenbacher. $2005 \mathrm{~b}$. Additional microsatellite markers of the european hazelnut. Acta Hort. 686:105-110.

Boccacci, P., A. Akkak, N.V. Bassil, S.A Mehlenbacher, and R. Botta. 2005. Characterization and evaluation of microsatellite loci in European hazelnut (Corylus avellana L.) and their transferability to other Corylus species. Mol. Ecol. Notes 5:934-937.

Cameron, H.R. 1976. Eastern filbert blight established in the Pacific Northwest. Plant Dis. Reporter 60:737-740.

Chen, H., S.A. Mehlenbacher, and D.C. Smith. 2005. AFLP markers linked to eastern filbert blight resistance from OSU 408.040 hazelnut. J. Amer. Soc. Hort. Sci. 130:412-417.

Chen, H., S.A. Mehlenbacher, and D.C. Smith. 2007. Hazelnut accessions provide new sources of resistance to eastern filbert blight. HortScience 42:466-469.

Coyne, C.J., S.A. Mehlenbacher, R.O. Hampton, J.N. Pinkerton, and K.B. Johnson. 1996. Use of ELISA to rapidly screen hazelnut for resistance to eastern filbert blight. Plant Dis. 80: 1327-1330.

Coyne, C.J., S.A. Mehlenbacher, and D.C. Smith 1998. Sources of resistance to eastern filbert blight in hazelnut. J. Amer. Soc. Hort. Sci. 123: 253-257.

Davison, A.R. and R.M. Davidson, Jr. 1973 Apioporthe and Monochaetia cankers reported in western Washington. Plant Dis. Reporter 57: $522-523$.

FAOStat. 2009. 22 Dec. 2011. <http://faostat.fao.org/ site $/ 567 /$ default.aspx $>$.

Gürcan, K. and S.A. Mehlenbacher. 2010a. Development of microsatellite marker loci for European hazelnut (Corylus avellana L.) from ISSR fragments. Mol. Breed. 26:551-559.

Gürcan, K. and S.A. Mehlenbacher. 2010b. Transferability of microsatellite markers in the Betulaceae. J. Amer. Soc. Hort. Sci. 135:159-173.

Gürcan, K., S.A. Mehlenbacher, N.V. Bassil, P. Boccacci, A. Akkak, and R. Botta. 2010. Development, characterization, segregation, and mapping of microsatellite markers for european hazelnut (Corylus avellana L.) from enriched genomic libraries and usefulness in genetic diversity studies. Tree Genet. Genomes 6:513531.

Johnson, K.B., S.A. Mehlenbacher, J.K. Stone, and J.W. Pscheidt. 1996. Eastern filbert blight of European hazelnut-It's becoming a manageable disease. Plant Dis. 80:1308-1316.

Lunde, C.F., S.A. Mehlenbacher, and D.C. Smith. 2000. Survey of hazelnut cultivars for response to eastern filbert blight inoculation. HortScience 35:729-731.

Mehlenbacher, S.A. 1994. Genetic improvement of hazelnut. Acta Hort. 351:23-28.

Mehlenbacher, S.A., R.N. Brown, J.W. Davis, H. Chen, N. Bassil, and D.C. Smith. 2004. RAPD markers linked to eastern filbert blight resistance in Corylus avellana. Theor. Appl. Genet. 108:651-656.

Mehlenbacher, S.A., R.N. Brown, E.R. Nouhra, T. Gökirmak, N.V. Bassil, and T.L. Kubisiak. 2006. A genetic linkage map for hazelnut (Corylus avellana L.) based on RAPD and SSR markers. Genome 49:122-133.

Mehlenbacher, S.A., M.M. Thompson, and H.R. Cameron. 1991. Occurrence and inheritance of resistance to eastern filbert blight in 'Gasaway' hazelnut. HortScience 26:410-411.
Michelmore, R.W. and B.C. Meyers. 1998. Clusters of resistance genes in plants evolve by divergent selection and a birth-and-death process. Genome Res. 8:1113-1130.

Molnar, T.J., J.C. Goffreda, and C.R. Funk. 2010a. Survey of Corylus resistance to Anisogramma anomala from different geographic locations. HortScience 45:832-836.

Molnar, T.J., J. Capik, S. Zhao, and N. Zhang. 2010b. First report of eastern filbert blight on Corylus avellana 'Gasaway' and 'VR20-11' caused by Anisogramma anomala in New Jersey. Plant Dis. 94:1265.

Pinkerton, J.N., K.B. Johnson, S.A. Mehlenbacher, and J.W. Pscheidt. 1993. Susceptibility of European hazelnut clones to eastern filbert blight. Plant Dis. 77:261-266.

Pinkerton, J.N., K.B. Johnson, J.K. Stone, and K.L. Ivors. 1998a. Factors affecting the release of ascospores of Anisogramma anomala. Phytopathology 88:122-128.

Pinkerton, J.N., K.B. Johnson, J.K. Stone, and K.L. Ivors. 1998b. Maturation and seasonal discharge pattern of ascospores of Anisogramma anomala. Phytopathology 88:1165-1173.

Pinkerton, J.N., K.B. Johnson, K.M. Theiling, and J.A. Griesbach. 1992. Distribution and characteristics of the eastern filbert blight epidemic in western Oregon. Plant Dis. 76:1179-1182.

Pinkerton, J.N., J.K. Stone, S.J. Nelson, and K.B. Johnson. 1995. Infection of European hazelnut by Anisogramma anomala: Ascospore adhesion, mode of penetration of immature shoots, and host response. Phytopathology 88:12601268.

Pscheidt, J.W. 2006. Potential EFB control programs. Proc. of the Nut Growers Society of Oregon, Washington and British Columbia 91: 72-78.

Sathuvalli, V.R., S.A. Mehlenbacher, and D.C. Smith. 2010. Response of hazelnut accessions to greenhouse inoculation with Anisogramma anomala. HortScience 45:1116-1119.

Sathuvalli, V.R., H. Chen, S.A. Mehlenbacher, and D.C. Smith. 2011a. DNA markers linked to eastern filbert blight resistance in 'Ratoli' hazelnut (Corylus avellana L.). Tree Genet. Genomes 7:337-345.

Sathuvalli, V.R., S.A. Mehlenbacher, and D.C. Smith. 2011b. DNA markers linked to eastern filbert blight resistance from a hazelnut selection from the Republic of Georgia. J. Amer. Soc. Hort. Sci. 136:350-357.

Sathuvalli, V.R. and S.A. Mehlenbacher. 2011. Characterization of American hazelnut (Corylus americana) accessions and Corylus americana $\times$ Corylus avellana hybrids using microsatellite markers. Genet. Res. Crop Evol. (in press). DOI: 10.1007/s10722-011-9743-0.

Stone, J.K., K.B. Johnson, J.N. Pinkerton, and J.W. Pscheidt. 1992. Natural infection period and susceptibility of vegetative seedlings of European hazelnut to Anisogramma anomala. Plant Dis. 76:348-352.

Van Olijen, G., H.A. van den Burg, B.J.C. Cornelissen, and F.L.W. Takken. 2007. Structure and function of resistance proteins in Solanaceous plants. Annu. Rev. Phytopathol. 45:43-72.

Van Ooijen, J.W. and R.E. Voorrips. 2006. JoinMap 4.0, Software for the calculation of genetic linkage maps. Kyazama B.V., Wageningen, The Netherlands.

Williams, J., A. Kubelik, K. Livak, J. Rafalski, and S. Tingey. 1990. DNA polymorphisms amplified by arbitrary primers are useful as genetic markers. Nucleic Acids Res. 18:6531-6535. 